Rev. Bras. Saúde Prod. Anim., Salvador, v.14, n.1, p.91-103 jan./mar., 2013 http://www.rbspa.ufba.br ISSN 15199940

\title{
Tendências metodológicas para avaliação da adaptabilidade ao ambiente tropical $^{1}$
}

\author{
Methodological tendencies of adaptability evaluation to tropical environment
}

\author{
FAÇANHA, Débora Andréa Evangelista ${ }^{2 *}$; CHAVES, Dowglish Ferreira ${ }^{3}$; MORAIS, \\ Jacinara Hody Gurgel ${ }^{2}$; VASCONCELOS, Ângela Maria de ${ }^{4}$; COSTA, Wirton Peixoto ${ }^{2}$; \\ GUILHERMINO, Magda Maria ${ }^{5}$
}

\author{
${ }^{1}$ Revisão apresentada no Congresso Brasileiro de Zootecnia (ZOOTEC 2011). \\ ${ }^{2}$ Universidade Federal Rural do Semi-Árido, Departamento de Ciências Animais, Mossoró, Rio Grande do \\ Norte, Brasil. \\ ${ }^{3}$ Universidade Federal Rural do Semi Árido, Programa de Pós-Graduação em Produção Animal, Rio Grande \\ do Norte, Brasil. \\ ${ }^{4}$ Universidade Estadual Vale do Acaraú, Sobral, Ceará, Brasil. \\ ${ }^{5}$ Universidade Federal do Rio Grande do Norte, Departamento de Agropecuária, Natal, Rio Grande do \\ Norte, Brasil. \\ *Endereço para correspondência: debora_ufersa@hotmail.com
}

\section{RESUMO}

A adaptação dos animais ao ambiente criatório é essencial para o êxito de qualquer empreendimento pecuário. No Brasil, há algumas décadas, foram importadas inúmeras raças, oriundas de clima temperado, das mais diversas espécies de animais de produção, cujas progênies eram avaliadas e selecionadas em consideração apenas dos aspectos produtivos. Nos últimos dez anos, verificou-se que tanto criadores, como a comunidade acadêmica, despertaram para a valorização de aspectos adaptativos, ao selecionarem animais a serem criados nos mais diversos biomas brasileiros. Observa-se, assim, a valorização das raças nativas de pequenos ruminantes e zebuínos para a exploração de carne e leite. No entanto, avaliar e selecionar animais pelas características adaptativas requer uma padronização de parâmetros e metodologias para a colheita de dados confiáveis. Ao se considerar que a homeostase representa a condição de equilíbrio em um sistema biológico e que animais adaptados ao ambiente exibem claros sinais de homeostasia, procurou-se, neste trabalho, abordar uma metodologia fundamentada numa matriz multifatorial para avaliar a adaptação, na qual são consideradas as reações termorreguladoras, como forma de manter a homeotermia, indicadas pelas temperaturas retal e de superfície, acionamento da termólise evaporativa, representadas pela frequência respiratória e taxa de sudação. Para avaliação da homeostase recomendase a associação de reações endócrinas, tais como níveis circulantes de hormônios da tireoide e cortisol, aos parâmetros bioquímicos dentro da faixa de normalidade. Todos esses fatores, em equilíbrio, permitem aos animais expressar satisfatoriamente as funções reprodutiva e produtiva.

Palavras-chave: adaptação, animais de produção, metodologia.

\section{SUMMARY}

The adaptation of animals to breeding environment is essential to the success of any livestock enterprise. In Brazil, some decades ago, several breeds were imported, originated from temperate climates, from various species of farm animals whose progeny were evaluated and selected taking into account only the productive aspects. In the last ten years it was found that both creators and the academic community awoke to the promotion of adaptive aspects when selecting animals to be created in many different biomes. There is thus, the recovery of native breeds of 
zebu cattle and small ruminants for meat and milk productions. However, evaluate and select animals for adaptive traits require the standardization of parameters and methodologies for the collection of reliable data. Whereas homeostasis represents the equilibrium condition in a biological system and that animals adapted to the environment exhibit clear signs of homeostasis, this study sought to address a methodology composed of a multifactorial matrix to evaluate the adaptation, which are considered the thermoregulatory reactions As a way to maintain homeothermy indicated by rectal and surface temperatures and activation of evaporative heat loss, represented by the respiratory rate and sweating rate. For evaluation of homeostasis is recommended the association of endocrine reactions, such as circulating levels of thyroid hormones and cortisol, to the biochemical parameters within the normal range. All of these factors in balance allow the animals to express satisfactorily the reproductive and productive roles.

Keywords: adaptation, livestock, metodology.

\section{INTRODUÇÃO}

A maioria dos animais domésticos criados nos países tropicais descende de espécies introduzidas pelos colonizadores europeus, as quais, durante o período de seleção natural, adquiriram caracteres que possibilitaram sua adaptaçao às temperaturas elevadas, aos agentes patogênicos, aos parasitos e à alimentação peculiares às novas condições (SILVA, 2008). No início do século XX, no sentido de aumentar a produtividade, foram importadas raças exóticas, de clima temperado, o que causou uma drástica substituição das raças nativas, cujas progênies apenas eram selecionadas pela produtividade (EGITO et al., 2002). Entretanto, o sucesso de uma criação depende da escolha de genótipos melhor adaptados às condições climáticas de uma determinada região, que deve considerar, além da capacidade de ganho de peso, rendimento de carcaça e produção de leite, aspectos adaptativos, como prolificidade e sobrevivência.

Os elementos climáticos são fatores ambientais marcantes, pois impõem a necessidade de termorregular e podem reduzir o consumo voluntário e, com isso, o desempenho (BROUCEK et al., 2009). Em vacas leiteiras, por exemplo, um dos maiores entraves é associar genótipos produtivos a animais adaptados ao calor, pois, sobretudo os mais produtivos, apresentam quedas importantes no consumo de alimentos e na produção (FAÇANHA-MORAIS et al., 2008).

Existem dois caminhos para o incremento da produção na região tropical: o primeiro consiste em utilizar genótipos mais produtivos e fornecer-lhes um ambiente compatível com os seus requerimentos. $\mathrm{O}$ segundo se refere à utilização de animais adaptados, dos quais se devem selecionar os mais produtivos. Nesse caso, a utilização de raças nativas assume um importante papel, devido ao seu grande potencial adaptativo ao ambiente.

Ao se tratar de animais de produção, adaptação não significa apenas sobrevivência, mas também reprodução e produção condizentes com sua utilização nos sistemas produtivos. Segundo Sejian et al. (2010), animais criados em regiões semiáridas, geralmente expostos a diversos fatores estressantes, podem adaptar-se mediante a termorregulação, porém, em detrimento de outras funções orgânicas, sobretudo as relacionadas à produção e reprodução. Nesse contexto, características de pelame e epiderme, reações como taquipineia e sudação são importantes termorreguladores, cuja associação à respostas endócrinas, bioquímicas $\mathrm{e}$ hematológicas permite inferir sobre a 
homeostase, de modo a se configurar como indicadores seguros de adaptabilidade.

\section{ADAPTABILIDADE AO AMBIENTE TROPICAL: HOMEOSTASE E PRODUÇÃO}

O termo "homeostase", formado pelos radicais gregos homeo (o mesmo) e stasis (ficar) foi criado para significar a manutenção de condições constantes no meio interno. A homeostasia é a propriedade autorreguladora de um sistema, ou organismo, que permite manter uma condição interna estável, mediante múltiplos ajustes de equilíbrio dinâmico, controlados por mecanismos de regulação inter-relacionados. Sua principal vantagem é permitir um funcionamento mais eficiente do organismo no meio ao qual este se adaptou.

Dentro do contexto de produção, ao se considerar que a maioria dos animais criados em ambiente tropical são homeotermos, estes devem ser capazes de manter a temperatura corporal dentro de limites fisiológicos, mesmo em face de variações ambientais (SILVA, 2008). Muitos são os mecanismos utilizados para este fim, porém, quase todos interferem na fisiologia, o que implica alterações nas funções produtivas. Diante do exposto, selecionar animais adaptados às particularidades do ambiente criatório significa trabalhar com organismos o mais próximo possível da homeostase, o que deve ser confirmado por indicadores fisiológicos normais, como temperatura corporal, perfil hormonal, bioquímico e hematológico, crescimento, função reprodutiva e produção de leite, entre outros.
Sem dúvida alguma, o problema da produção animal em ambiente tropical foi, durante muito tempo, atribuído à alimentação deficiente, à inadequação do clima tropical à criação de animais de alta produção e à incapacidade dos produtores em absorver a tecnologia adotada nos países de clima temperado. Na realidade, as raças de clima temperado introduzidas no continente americano se adaptaram às regiões temperadas, mas não às regiões tropicais. Procurava-se melhorar o desempenho dos animais com base no critério de melhoramento europeu: "seleção para maior produtividade".

O resultado dessas ações foi que, após anos de investimento em raças de clima temperado, verificaram-se vários problemas decorrentes da utilização desses genótipos no clima quente, e modificar o ambiente através do uso de equipamentos refrigeradores significava onerar substancialmente o sistema de produção, às vezes sem êxito no incremento produtivo, conforme verificado por Laloni et al. (2004). Assim, as estratégias começaram a mudar o foco para a seleção de animais portadores de atributos que favorecessem a dissipação de calor, de modo a possibilitar maior expressão dos mecanismos homeostáticos, o que por sua vez se reflete no maior desempenho produtivo.

As primeiras ações que consideravam a importância dos aspectos adaptativos ocorreram por volta de 1945, quando foram realizados os primeiros cruzamentos entre raças europeias e tropicais para se avaliar produção e adaptação. A primeira edição do "Manual de Estudos de Campo em Tolerância ao Calor" foi publicada por Lee (1953) como guia prático para a seleção de animais adaptados ao clima tropical. 
Em seguida, surgiram os primeiros testes de tolerância ao calor, Teste de Ibéria (Rhoad), o Índice de Tolerância ao calor de Bonsma, entre outros. No entanto, apesar do inestimável valor científico e da ampla utilização durante anos pelos pesquisadores, a maioria desses testes era baseado apenas na temperatura retal. Esse fator, além de resultar em conclusões equivocadas sobre a avaliação da adaptabilidade, limitou seu uso para animais que evoluíram em clima quente, uma vez que nem sempre a temperatura corporal mais elevada significa menor adaptação ao calor.

Animais que evoluem em clima quente e seco utilizam estratégias fisiológicas para evitar a perda excessiva de água. Eles desenvolvem uma capacidade de armazenar energia no interior de organismo de modo a não haver necessidade de acionar os mecanismos evaporativos de termólise, ou seja, acumulam calor durante as horas mais quentes do dia, de forma a entrar em equilíbrio com o ambiente. Assim, atribuir a um grupo genético adaptado ao semiárido, por exemplo, um menor grau de adaptabilidade em virtude de uma temperatura corporal mais elevada, pode ser uma conclusão totalmente equivocada (SWENSON \& REECE, 1998; SILVA, 2008).

Segundo Maia et al. (2003), algumas características que conferem um maior grau de adaptabilidade ao calor, e considerà-las como critério de seleção para adaptação ao clima tropical. Alguns desses atributos foram identificados por Façanha-Morais et al. (2010) como predominantes em vacas leiteiras evoluídas, durante várias gerações, em ambiente semiárido. as quais conseguiram manter a homeostase, indicada por temperatura corporal normal e estável, atividade normal da glândula tireoide e produção satisfatória de leite em todas as épocas do ano (FAÇANHA-MORAIS, et al., 2008).

\section{CARACTERÍSTICAS A CONSIDERAR NAS AVALIAÇÕES DA ADAPTABILIDADE CAPA EXTERNA}

A radiação solar direta é, em parte, refletida de acordo com a cor e outras propriedades do pelame do animal, e a parte restante, absorvida sob a forma de calor. Dessa forma, a capa externa do organismo constituída de pelame, ou velo, nos mamíferos e de penas e penugem nas aves, assume fundamental importância para as trocas térmicas, de modo a influenciarem profundamente o balanço térmico dos mesmos (SILVA, 2008).

Segundo Silva (1999), um animal mais adequado para ser criado a campo aberto em regiões tropicais deve apresentar um pelame claro com pelos curtos, grossos, medulados e bem assentados, sobre uma epiderme altamente pigmentada. Tais características favorecem tanto a convecção como a evaporação na superfície cutânea, ao passo que altos níveis de melanina na epiderme protegem contra a radiação ultravioleta.

Silva et al. (2009) conduziram um estudo para identificar o melhor método de estimar a energia total radiante absorvida por vacas leiteira mestiças, criadas a campo, em regiões de baixa latitude. Os autores concluíram que nessas áreas os animais com predominância de pelame negro devem ser preferidos, pois contam com a proteção da epiderme pigmentada, contra os efeitos danosos da radiaçao de ondas curtas, embora absorvam maior fração de radiação e se aqueçam mais.

Ao avaliarem a variabilidade do pelame e da epiderme em bovinos crioulos 
Limoneiro, na Venezuela, Landaeta et al. (2011) verificaram um subgrupo numeroso, selecionado pelos produtores, portadores de pelame vermelho claro, epiderme pigmentada e espessa, os quais apresentavam também glândulas sudoríparas volumosas e funcionais e pelos mais curtos.

Maia et al. (2003), em estudo das características físicas do pelame de vacas holandesas em região tropical, constataram que uma maior área de sua superfície corpórea coberta por malhas negras nos animais eram mais vantajosa do ponto de vista adaptativo, pois apresentavam pelos mais curtos, mais grossos e menos numerosos e isso oferecia uma menor resistência à termólise por convecção e evaporação cutânea. Na mesma pesquisa, verificaram que a epiderme despigmentada apresentou coeficiente de transmissão consideravelmente mais elevado do que a epiderme pigmentada, o que constitui uma característica desfavorável para animais em ambiente tropical.

Façanha et al. (2010) observaram, em vacas leiteiras mestiças no Sertão Central do Ceará, a ocorrência de pelames menos densos, com pelos mais curtos e assentados nas épocas em que se registraram maiores valores de temperatura radiante média. Esse tipo de pelame apresenta menor resistência ao fluxo de calor latente e sensível através da capa, ao mesmo tempo em que apresenta menor transmissividade efetiva da radiação absorvida na superfície do animal.

Leva-se em consideração que a quantidade de radiação transmitida através da capa de pelame depende da combinação de fatores como cor e estrutura física, principalmente densidade numérica. Esses autores sugerem a inclusão de características como espessura da capa e densidade numérica do pelame, pigmentação do pelame e da epiderme, assim como comprimento dos pelos nos protocolos de avaliação da adaptabilidade, uma vez que interferem nas trocas térmicas entre o animal e o ambiente e geralmente estão relacionadas a genes que conferem maior tolerância ao calor, em conformidade com Oslon et al. (2003).

Segundo Prayaga (2003), o tipo de pelame é um fator determinante do controle da temperatura corporal. No seu estudo, as correlações fenotípicas evidenciaram associações lineares e significativas entre o tipo de pelame e temperatura corporal $(0,39)$; pelame e ganho de peso $(-0,35)$ e entre temperatura corporal e ganho de peso $(-0,35)$, medidos em raças puras.

Olson et al. (2003) observou ainda que a temperatura corporal $0,34^{\circ} \mathrm{C}$ é mais baixa em bovinos cruzados 3/4 Holstein: 1/4 Senepol, na Flórida, classificados com tipo de pelame curto e bem assentado. Ligeiro et al. (2006), ao avaliarem as características de pelame de cabras mestiças $1 / 2$ Bôer $1 / 2$ Saanen e puros das raças Saanen e Alpina, observaram que, em geral, os caprinos possuem pelame menos denso que o de bovinos, formado por pelos finos e compridos.

Essa característica pode ser favorável em ambientes quentes, se for considerada a maior circulação ventosa entre os pelos que remove o ar aprisionado no interior da capa e consequentemente aumenta a perda de calor (convecção forçada). A pele protege o organismo do calor e do frio e sua temperatura depende, principalmente da umidade, vento, e das condições fisiológicas, como a vascularização e a sudação (SILVA, 2008). 


\section{TEMPERATURA CORPORAL E TERMÓLISE EVAPORATIVA}

Em certos habitats como desertos, regiões tropicais áridas e semiáridas, a temperatura do ar pode exceder facilmente a do organismo dos animais e ser agravada ainda pela radiação intensa e pela baixa umidade atmosférica. Nessas condições térmicas, as perdas de calor latente, sobretudo por evaporação cutânea, são as mais significativas.

Maia et al. (2009), por exemplo, observaram que, em vacas da raça holandesa expostas à temperaturas superiores a $27^{\circ} \mathrm{C}$, a evaporação cutânea respondia por $80 \%$ da evaporação total e que estava correlacionada negativamente à umidade do ar. Isso confirma que quanto mais seco é o ambiente, maior é o desgaste decorrente dos mecanismos termorreguladores.

A adaptabilidade de um animal depende basicamente de sua capacidade de manter dentro do padrão fisiológico sua temperatura corporal, para isso utilizam diversos mecanismos homeotérmicos. Porém, é importante salientar que a termorregulação possui valor adaptativo, mas, a depender da magnitude e da cronicidade, a utilização dos mecanismos pode impor sérias consequências ao desempenho dos animais. Daí a importância de se trabalhar com animais adaptados e sob condições adequadas de manejo.

Estabelecer os horários do dia em que certos ambientes impõem maior estresse pode ajudar a identificar os mecanismos mais utilizados pelas diversas espécies e raças e a traçar estratégias de manejo que contemplam a maior tolerância desses animais ao ambiente térmico. Nesse sentido, Silva (2010), ao estudar as variações circadianas de respostas termorreguladoras em ovinos Morada Nova, em Mossoró-RN, verificou que esses animais, identificados empiricamente como um modelo da adaptação ao ambiente semiárido, utilizavam em todos os horários do dia a termólise respiratória como resposta imediata à elevação da temperatura ambiente. Todavia, a evaporação cutânea ocorria com maior intensidade entre 5:00h e 8:00h, o que sugere a utilização da estocagem térmica como mecanismo de equilíbrio entre os animais e o ambiente.

O contrário foi verificado por Starling et al. (2002) em ovinos Corriedale lanados em câmara climática, os quais utilizaram em maior intensidade a evaporação respiratória, devido à resistência do velo à termólise cutânea. Sevi et al. (2001) verificaram que a redução da carga de calor sobre os animais, nas horas mais quentes do dia, quando associada à administração de alimentos em horários de temperatura mais amena, minimizou os impactos do estresse térmico sobre a ingestão dos alimentos, imunidade e saúde do úbere em ovelhas leiteiras.

McManus et al. (2009), em estudos com ovinos, observaram que o incremento da frequência respiratória observado pode ser considerado o principal mecanismo de controle da homeotermia sob as condições ambientais impostas, acompanhado pela taxa de sudação que atua na perda de calor. Estudos como esse mostram que o acionamento eficiente desses mecanismos confere a homeostasia do organismo animal e reforçam a sua importância como indicadores de adaptabilidade. 


\section{ASPECTOS ENDÓCRINOS DA ADAPTABILIDADE}

A homeostase é coordenada por processos fisiológicos, através de comunicação nervosa ou química entre os tecidos, na qual os hormônios desempenham papel decisivo. Dessa forma, as alterações dos níveis circulantes de hormônios são respostas endócrinas importantes na avaliação do estresse, em animais de interesse zootécnico, e podem, inclusive, refletir o efeito desse estresse sobre as funções produtivas (SCHIMIDTNIELSEN, 2002).

Quando um animal é exposto a um ambiente inadequado, uma das primeiras reações fisiológicas é a ativação do eixo hipotálamo-hipófise-adrenal, que envolve mudanças em todo o sistema endócrino. A porção cortical representa cerca de $80 \%$ das adrenais e é responsável pela produção de glicocorticoides, também chamados de hormônios da adaptação, atuantes na regulação de todos os aspectos do metabolismo. A resposta da adrenal ao estresse agudo ocorre com o aumento da secreção dos glicocorticoides, sobretudo o cortisol, usado como indicador de estresse, cujo efeito catabólico resulta em degradação dos tecidos e disponibilização de glicose aos tecidos nobres. Em contraste, a cronicidade do estímulo estressante pode levar à redução na atividade daquele eixo, no sentido de minimizar a mobilização excessiva dos tecidos, com efeitos decrementais ao crescimento, reprodução e lactação (SCHIMIDT-NIELSEN, 2002).

$\mathrm{O}$ estresse calórico afeta vários hormônios importantes para a lactação. Há diminuição nas secreções do hormônio do crescimento $(\mathrm{GH})$, tiroxina, triiodotironina, entre outros, com consequentes declínios na produção de leite, especialmente em vacas em estágios iniciais da lactação. Essas informações sobre as alterações hormonais fornecem embasamento fisiológico para a compreensão dos meios pelos quais o calor ambiental altera o processo de lactação e traz, como consequência, prejuízos aos sistemas produtivos.

A glândula tireoide é uma das mais envolvidas nos processos metabólicos globais e secreta duas iodotironinas, a Tiroxina $\left(\mathrm{T}_{4}\right)$ e a Triiodotironina $\left(\mathrm{T}_{3}\right)$, peculiarmente caracterizadas por sua atividade calorigênica, que afeta $o$ metabolismo de gorduras, carboidratos e proteínas, de maneira a controlar a termogênese obrigatória. Dentre as respostas hormonais ao estresse térmico, uma das mais importantes é a alteração do eixo hipotálamo-hipófise-tireoide, cuja reação no calor é reduzir sua atividade e, consequentemente, a taxa metabólica. Tais alterações possibilitam o equilíbrio de certas funções orgânicas relacionadas à termorregulação, porém podem causar prejuízos aos processos de síntese $\mathrm{e}$ secreção do leite e crescimento. A atividade sintética e secretora da tireoide é basicamente controlada pela secreção epifisária de tirotrofina (TSH), a qual também é influenciada por fatores ambientais, como flutuações sazonais da temperatura do ar. (SWENSON \& REECE, 1998).

Façanha-Morais et al. (2008) avaliaram o comportamento anual de respostas termorreguladoras de vacas leiteiras adaptadas às condições do Sertão Central do Ceará e verificaram semelhança da temperatura retal, entre as épocas do ano, e concentrações séricas de $T_{3}$ e $T_{4}$ menores do que as verificadas em vacas de alta produção, provavelmente devido à menor taxa metabólica necessária aos 
animais que se adaptaram ao clima quente.

\section{PARÂMETROS HEMATOLÓGICOS E BIOQUÍMICOS}

Alterações na produtividade pelo efeito do estresse calórico normalmente estão associadas ao baixo consumo de alimentos pelos animais e são seguidas pela diminuição da atividade enzimática oxidativa, da taxa metabólica e da alteração da concentração de vários hormônios (PEREIRA et al., 2008). A mensuração de parâmetros clínicos e hematológicos pode ser indicada para avaliar o bem-estar de bovinos, haja vista, durante o estresse hipertérmico, ter se observado que as concentrações de metabólitos intermediários, hemoglobina se alteram com a diminuição do volume plasmático, ocorre aumento dos neutrófilos, e decréscimo dos eosinófilos (BROUCEK et al., 2009).

A água é o elemento mais importante para os animais sob estresse térmico, por se tratar de um veículo eficiente de remoção de calor. No entanto, estresse pelo calor tende a aumentar o consumo de água e diminuir a quantidade de alimento ingerido, o que pode, em alguns casos, alterar os metabólitos sanguíneos em função do menor aporte de nutrientes (WEST, 2003). Em bovinos da raça Sindi, no semiárido da PB, Souza et al. (2007) verificaram diminuições nos eritrócitos, hemoglobina, hematócrito e volume corpuscular média, na estação seca, quando normalmente ocorre redução quantitativa e qualitativa dos recursos alimentares.

Brasil et al. (2000) verificaram redução do volume corpuscular médio e do hematócrito, associadas à maior perda de água pela termólise evaporativa, em cabras da raça Parda Alpina submetidas a estresse térmico. Essas alterações foram acompanhadas por redução na produção de leite e nas concentrações de gordura proteínas e sólidos totais.

Ferreira et al. (2009), ao avaliarem bovinos durante seis horas em câmara climática, submetidos à condições de estresse calórico $\left(42^{\circ} \mathrm{C}\right.$ e $60 \%$ de umidade relativa), observou um aumento do número de eritrócitos, concentração de hemoglobina, hematócrito, proteínas totais, ureia, creatinina, sódio, potássio, cloretos e cortisol, cuja elevação de todas essas variáveis foi mais acentuada no verão. Esses resultados demonstraram a importância desses parâmetros como indicadores do estresse calórico em bovinos, pois as respostas hematológicas e bioquímicas apresentadas indicaram possíveis falhas na manutenção da homeostasia do animal na condição climática imposta.

Atualmente, estudos para avaliação de adaptabilidade se encontram cada vez mais amplos e envolvem parâmetros até então pouco observados na bioclimatologia animal. Nesse sentido, novas abordagens para avaliação da adaptabilidade tornam-se necessárias a fim de se alcançar uma melhor compreensão dos processos de relação animal-ambiente. Dessa forma, passar-seia a considerar os parâmetros sanguíneos como indicadores homeostáticos, cujas modificações drásticas em seus valores podem causar desequilíbrios orgânicos, que representam a baixa eficiência de adaptação fisiológica (BROUCEK et al., 2009). 


\section{ASPECTOS PRODUTIVOS E DE DESEMPENHO}

Animais bem adaptados são caracterizados pela atenuação ou perda mínima de produção durante o período de estresse. Estes apresentam elevada eficiência reprodutiva, alta resistência a doenças, longevidade e baixa taxa de mortalidade (McMANUS et al., 2009). O crescimento, a reprodução e a lactação são controlados pelo sinergismo de um complexo hormonal, do qual fazem parte a somatotropina, as gonadotrofinas, estrógenos, progesterona, a ocitocina, os hormônios tireoidianos e córtico-adrenais. Assim, animais expostos ao estresse térmico podem apresentar quedas no desempenho em todas as esferas controladas por esses hormônios, com prejuízos ao processo produtivo.

A seleção de animais com maior habilidade para sobreviver, produzir e reproduzir-se em condições tropicais, assim como conhecer a capacidade adaptativa das raças exploradas no Brasil para a produção de leite, é um fator determinante para aumentar a produtividade. Façanha-Morais et al. (2008) registraram médias de produção que variavam entre $12,0 \mathrm{~kg} / \mathrm{vaca} / \mathrm{dia} \mathrm{e}$ $16,0 \mathrm{~kg} / \mathrm{vaca} / \mathrm{dia}$, em rebanhos leiteiros constituídos por animais adaptados ao clima semiárido. Os maiores problemas referem-se a animais de alta produção, pois a produção de calor, com a síntese do leite, tende a assumir valores superiores, devido à intensa atividade metabólica e maior quantidade de alimento ingerido. Entretanto, em estresse calórico, o consumo de matéria seca e o desempenho de bovinos podem ser reduzidos, também, por influência da intensidade e da duração do estímulo estressante, ou mesmo, pela interação entre densidade energética da ração e a temperatura efetiva à qual os animais estão submetidos (WEST, 2003).

Segundo Marai et. al. (2008), a exposição ao estresse por calor afeta a reprodução, isto é, provoca uma série de mudanças drásticas nas funções biológicas dos animais e esse efeito ainda é agravado pela elevada umidade, conforme citado por Wilson et al. (1998). Para ilustrar tais afirmações, esses autores verificaram inibição do crescimento e da dominância folicular e menor tamanho dos folículos dominantes da segunda onda, além de diminuição na secreção de estradiol com consequente expansão da fase lútea em vacas expostas ao estresse térmico. Em termos práticos, essas alterações podem prejudicar o manejo reprodutivo, através de falhas na detecção do estro, o que leva à redução da taxa de prenhez do rebanho. De Rensis \& Scaramuzzi (2003) confirmam que o estresse térmico pode reduzir a duração, a intensidade e a expressão dos sinais de estro, cuja consequência é a maior proporção de inseminações que não resultam em prenhez.

Nos machos, as altas temperaturas podem provocar esterilidade estival, degeneração do epitélio germinativo, redução da produção de sêmen e queda de fertilidade. O estresse calórico pode afetar o ganho de peso e promover retardo na puberdade de ovinos (MARAI et al., 2008). Entretanto, essas características não apresentam a mesma magnitude quando tratamos de animais adaptados.

Pezzini et al. (2006) constataram maior redução na motilidade espermática, menores vigor e número total de espermatozoides em bovinos da raça Holandesa submetidos à insulação testicular, quando comparados aos Curraleiros, o que foi atribuído à maior 
adaptação desses últimos ao ambiente tropical.

Dessa forma, ao considerar que a reprodução é o mecanismo de propagação das características que garantem o aumento das populações, os indicadores da função reprodutiva tais como fertilidade, prolificidade e comportamento reprodutivo devem ser incluídos nos protocolos de avaliação da adaptabilidade ao ambiente. Outros aspectos relacionados ao desempenho são: avaliação da condição corporal das matrizes e habilidade materna, uma vez que estão diretamente vinculados à taxa de sobrevivência das crias, portanto, influenciam a adaptação dos grupos genéticos ao ambiente onde evoluíram.

\section{MENSURAÇÕES AMBIENTAIS}

Além dos aspectos animais, o ambiente deve ser corretamente mensurado, pois medidas inadequadas podem levar a conclusões equivocadas acerca das reações dos animais. Vários índices já foram propostos para revelar os diversos elementos ambientais que influenciam as reações dos animais. Dentre eles os mais utilizados são o THI (Temperature Humidity Index), o BGHI (Black Globe Humidity Index). Este foi desenvolvido para vacas leiteiras de alta produção. No entanto, Silva et al. (2007) verificaram que esses índices não foram correlacionados com as reações fisiológicas de vacas leiteiras mestiças em regiões de baixa latitude, por isso propuseram a utilização de ETI (Equivalent Temperature Index), desenvolvido por Baeta et al. (1987).

Quando os animais se encontram em ambiente termoneutro, os custos fisiológicos são mínimos e a produtividade é máxima. No entanto, na região tropical, ocorrem temperaturas acima dessa faixa, durante a maior parte do ano. Nesses casos, verifica-se o estresse térmico, cujos indicadores são mudanças na taxa metabólica, na temperatura corporal e na frequência respiratória. Quando os mecanismos de termólise não são suficientes, os animais passam a estocar calor, o que eleva sua temperatura corporal.

Em certas condições, a termólise evaporativa é o único meio efetivo de dissipação do excesso de calor corporal. A evaporação cutânea, por sua vez, representa cerca de $85 \%$ da perda de calor latente, e o restante é perdido através da evaporação respiratória. Essas informações chamam à atenção para a necessidade de se considerar uma matriz multifatorial na avaliação da adaptabilidade dos diferentes grupos genéticos às peculiaridades climáticas da região tropical.

Para tanto, é necessária uma criteriosa investigação sobre os mecanismos termorreguladores mais utilizados nas diversas espécies, seus efeitos sobre a homeostase e, obviamente, sobre o desempenho desses animais nas esferas produtiva, reprodutiva e sanitária. Tais informações são ferramentas importantes para o estabelecimento de estratégias de manejo e de seleção de genótipos criados em regiões com alta incidência de radiação.

\section{REFERÊNCIAS}

BAETA, F.C.; MEADOR, N.F.; SHANKLIN, M.D.; JHONSON, H.D.

Equivalent temperature index at temperatures above the thermoneutral for lactating cows. ASAE Paper No. 
Rev. Bras. Saúde Prod. Anim., Salvador, v.14, n.1, p.91-103 jan./mar., 2013 http://www.rbspa.ufba.br ISSN 15199940

874015. St. Joseph, MI: American Society of Agricultural Engineers, 1987. $21 \mathrm{p}$.

BRASIL, L.H.A.; WECHESLER, F.S.; BACCARI JUNIOR, F.; GONÇALVES, H.C.; BONASSI, I.A. Efeitos do estresse térmico sobre a produção, composição química do leite e respostas termorreguladoras de cabras da raça Alpina. Revista Brasileira de Zootecnia, v.29, n.6, p.1632-1641, 2000.

BROUCEK, J.; KISAC, P.; UHRINCAT, M. Effect of hot temperatures on the hematological parameters, health and performance of calves. International Journal of Biometeorology, v.15, p.201208, 2009.

DE RENSIS, F.; SCARAMUZZI, R.J. Heat stress and seasonal effects on reproduction in dairy cows - a review. Theriogenology, v.60, p.1139-1151, 2003.

EGITO, A.A.; MARIANTE, A.S.; ALBUQUERQUE, M.S.M. Programa brasileiro de conservação de recursos genéticos animais. Archivos de Zootecnia, v.51, n.4, p.39-52, 2002.

FAÇANHA-MORAIS, D.A.E.; MAIA, A.S.C.; SILVA, R.G.; VASCONCELOS, A.M.; LIMA, P.O.; GUILHERMINO, M.M. Variação anual de hormônios tireoidianos e características termorreguladoras de vacas leiteiras em ambiente quente. Revista Brasileira de Zootecnia, v.37, n.3, p.538-545, 2008.

FAÇANHA, D.A.E.; SILVA, R.G.; MAIA, A.S.C.; GUILHERMINO, M.M.; VASCONCELOS, A.M. Variação anual de características morfológicas e da temperatura de superfície do pelame de vacas da raça Holandesa em ambiente semiárido. Revista Brasileira de Zootecnia, v.39, n.4, p.837-844, 2010.

FERREIRA, F.; CAMPOS, W.E.; CARVALHO, A.U.; PIRES, M.F.A.; MARTINEZ, M.L.; SILVA, M.V.G.B.; VERNEQUE, R.S.; SILVA, P.F.

Parâmetros clínicos, hematológicos, bioquímicos e hormonais de bovinos submetidos ao estresse calórico. Arquivo Brasileiro de Medicina Veterinária e Zootecnia, v.61, n.4, p.769-776, 2009.

LALONI, L.A.; NAAS, I.A.; MACARI, M.; PEREIRA, D.F.; PINHEIRO, M.G. Índice de previsão de produção de leite para vacas Jersey. Engenharia Agrícola, v.24, n.2, p.246-254, 2004.

LANDAETA, A.H.; ZAMBRANO, S.N.; HERNANDEZ, F.J.P.; ROSARIO, G.; CALLES, M.; IRAGORRI, J.L.; ANEZ, L.; POLANCO, M.; MONTEIRO, U.M.; OLSON, T. Variability of hair coat and skin traits as related to adaptation in Criollo Limonero cattle. Tropical Animal Health and Production, v.43, n.3, p.657-663, 2011.

LEE, D.H.K; Manual of field studies on heat tolerance of domestic animals. Roma: FAO, 1993. 161p.

LIGEIRO, E.C.; MAIA, A.S.C.; SILVA, R.G.; LOUREIRO, C.M.B. Perda de calor por evaporação cutânea associada às características morfológicas do pelame de cabras leiteiras criadas em ambiente tropical. Revista Brasileira de Zootecnia, v.35, n.2, p.544-549, 2006. 
Rev. Bras. Saúde Prod. Anim., Salvador, v.14, n.1, p.91-103 jan./mar., 2013 http://www.rbspa.ufba.br ISSN 15199940

MAIA, A.C.; SILVA, R.G.;

BERTIPAGLIA, E.C.A. Característica do

Pelame de vacas Holandesas em ambiente

Tropical: um estudo genético e

adaptativo. Revista Brasileira de

Zootecnia, v.32, n.4, p.843-853, 2003.

MAIA, A.S.C.; SILVA, R.G.; SOUZA

JUNIOR, J.B.; SILVA, R.B.;

DOMINGOS, H.G.T. Effective thermal conductivity of the hair coat of holstein cows in a tropical environment. Revista

Brasileira de Zootecnia, v.38, n.11, p.1751-1760, 2009.

MARAI, I.F.M.; EL-DARAWANY, A.A.; FADIEL, A.; ABDEL-HAFEZ, M.A.M.

Reproductive performance traits as affected by heat Stress and its alleviation in sheep: a review. Tropical and

Subtropical Agroecosystems, n.8, p.209234, 2008.

McMANAUS, C.; PALUDO, G.R.; LOUVANDINI, H.; GUGEL, R.; SASAKI, L.C.B.; PAIVA, S.R. Heat tolerance in brazilian sheep: physiological and blood parameters. Tropical Animal Health Production, n.41, p.95-101, 2009.

OLSON, T.A.; LUCENA, C.; CHASE JUNIOR, C.C.; HAMMOND, A.C.

Evidence of a major gene influencing hair length and heat tolerance in Bos taurus cattle. Journal of Animal Science, v.81, p.80-90, 2003.

PEREIRA, C.J.; CUNHA, D.N.F.V.; CECON, P.R.; FARIA, P.R. Desempenho, temperatura retal e frequência respiratória de novilhas leiteiras de três grupos genéticos recebendo dietas com diferentes níveis de fibra. Revista Brasileira de Zootecnia, v.37, n.2, p.328-334, 2008.
PEZZINI, T.G.; SARTORI, R.; SILVA, T.A.S.N.; McMANUS, C.; MARIANTE, A.S. Características seminais de touros Curraleiros e Holandeses submetidos à insulação escrotal. Pesquisa

Agropecuária Brasileira, v.41, n.5, p.863-868, 2006.

PRAYAGA, K.C. Evaluation of beef cattle genotypes and estimation of direct and maternal genetic effects in a tropical environment. 1. Growth traits. Australian Journal of Agricultural Research, v.54, p.1013-1025, 2003.

\section{SCHIMIDT-NIELSEN, K. Fisiologia} animal: adaptação e meio ambiente. 5.ed. São Paulo: Santos, 2002. 546p.

SEJIAN, V.; MAURIA, V.P.; NAQVY, S.M.K. Adaptive capability as indicated by endocrine and biochemical responses of Malpura ewes subjected to combined stress (thermal and nutritional) in a semiarid tropical environment. International Journal of Biometeorology, v.54, p.653$661,2010$.

SEVI, A.; ANNICCHIARICO, ALBENZIO, M.; TAIBI, L.; MUSCIO, A.; DELL'AQUILA, S. Effects of solar radiation and feeding time on behavior, immune response and production of lactating ewes under ambient temperature. Journal of Dairy Science, v.84, n.3, p.629-640, 2001.

SILVA, R.G.; FAÇANHA-MORAIS, D.A.E.; GUILHERMINO, M.M.

Evaluation of thermal stress indexes for dairy cows in tropical regions. Revista Brasileira de Zootecnia, v.36, n.4, p.1192-1198, 2007. Suplemento especial. 
SILVA, R.G. Estimativa do balanço térmico por radiação em vacas Holandesas expostas ao sol e à sombra em ambiente tropical. Revista Brasileira de Zootecnia, v.28, n.6, p.1403-1411, 1999.

SILVA, R.G.; GUILHERMINO, M.M.; FAÇANHA, D.A.E. Thermal radiation absorbed by dairy cows in the pasture.

International Journal of

Biometeorology, v.47, p.23, 2009.

SILVA, R.G. Biofísica Ambiental "Os animais e seu ambiente". São Paulo: Funep. 2008. 450p.

SILVA, W.E. Variaçao diaria de respostas termorreguladoras $\mathrm{e}$ estocagem térmica em ovelhas Morada Nova. 2010. 43p.Trabalho de Conclusão de Curso (Zootecnia) - Universidade Federal Rural do Semi-Árido, Mossoró.

SOUZA, B.B.; SILVA, R.M.N.; MARINHO, M.L.; SILVA, G.A.; SILVA, E.M.N.; SOUZA, A.P. Parâmetros Fisiológicos e Índice de tolerância ao calor de bovinos da raça Sindi no semiárido paraibano. Ciência Agropecuária, v.31, n.3, p.883-888, 2007.
STARLING, J.M.C.; SILVA, R.G.; CERÓN-MUNÕZ, M.; BARBOSA, G.S.S.C.; COSTA, M.J.R.P. Análises de algumas variáveis fisiológicas para avaliação do grau de adaptação de ovinos submetidos ao estresse por calor. Revista Brasileira de Zootecnia, v.31, n.5, p.2070-2077, 2002.

SWENSON, M.J.; REECE, O.W. DUKES - Fisiologia dos Animais Domésticos. 11.ed. Rio de Janeiro: Guanabara, 1998. 856p.

WEST, J.W. Effects of heat-stress on production in dairy cattle. Journal Dairy Science, v.86, n.6, p.2131-2144, 2003.

WILSON, S.J.; MARION, R.S.; SPAIN, J.N.; SPIERS, D.E.; KEISLER, D.H.; LUCY, M.C. Effects of controlled heat stress on ovarian function of dairy cattle. Journal of Dairy Science, v.81, n.8, p.2124-2131, 1998.

Data de recebimento: 10/11/2011

Data de aprovação: 29/05/2012 